\title{
Prevention and management of penile prosthesis infections
}

\author{
Lael Reinstatler, Martin S. Gross
}

Section of Urology, Dartmouth-Hitchcock Medical Center, Lebanon, NH, USA

Contributions: (I) Conception and design: Both authors; (II) Administrative support: Both authors; (III) Provision of study materials or patients: Both authors; (IV) Collection and assembly of data: Both authors; (V) Data analysis and interpretation: Both authors; (VI) Manuscript writing: Both authors; (VII) Final approval of manuscript: Both authors.

Correspondence to: Martin S. Gross. Section of Urology, Dartmouth-Hitchcock Medical Center, 1 Medical Center Dr., Lebanon, NH 03756, USA.

Email: martin.s.gross@gmail.com.

\begin{abstract}
Penile prosthesis placement is the gold standard in surgical management of medically refractory erectile dysfunction. The malleable penile prosthesis (MPP) and the inflatable penile prosthesis (IPP) were both introduced in 1973, and there have been substantial changes to these devices and to surgical technique in the intervening five decades. These changes in device insertion and mechanical reliability have placed IPPs among the most reliable and satisfying prosthetic surgical devices. These improvements have also helped to drastically reduce penile prosthesis infection, which is widely considered the most dreaded complication of penile prosthesis surgery. There have also been significant advances in the management of penile prosthesis infection in the last 25 years. For patients, penile prosthesis infections can result in one (or more) reoperative procedures, loss of restored erectile function, penile length loss, and emotional trauma. For surgeons, penile prosthesis infections can be difficult to manage and can result in dire medicolegal repercussions. Even after years of progress in penile prosthesis infection prevention, infections still occur after a small percentage of primary penile prosthesis insertion cases. In addition, the increased risk of penile prosthesis infection associated with revision surgeries remains an issue. Penile prosthesis infection prevention factors include patient-dependent factors, surgeon- dependent factors, and device-dependent factors. In this video article we aim to review and summarize methods for penile prosthesis infection prevention and management.
\end{abstract}

Keywords: Inflatable penile prosthesis (IPP); infection; erectile dysfunction

Received: 11 December 2019. Accepted: 06 January 2020; Published: 20 January 2021.

doi: 10.21037 /jovs.2020.01.05

View this article at: http://dx.doi.org/10.21037/jovs.2020.01.05

\section{Introduction}

Inflatable penile prostheses (IPP) are the gold standard for medical refractory erectile dysfunction (1). First introduced in 1973, these devices have undergone many modifications over time with great improvement in device functionality and decreased device failure and infection complications (2). While several complications are possible after IPP surgery, infection is perhaps the most dreaded as it is results in not only patient and partner emotional and physical distress but is also a time-involved and expensive complication to manage (3-6). There are several key factors in managing penile prosthesis infection an these include clinical diagnosis, treatment, and important pre-operative and intraoperative steps (Video 1).

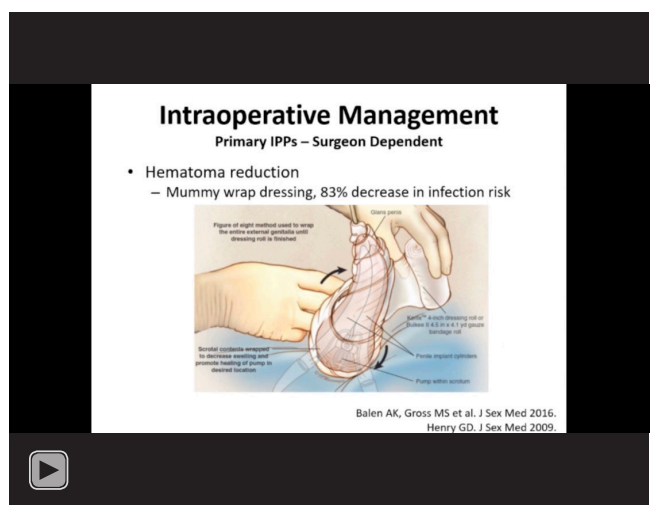

Video 1 Prevention and management of penile prosthesis infection. 
Table 1 Modifiable risk factors for IPP infection

\begin{tabular}{ll}
\hline Modifiable risk factors & Proposed intervention \\
\hline Primary surgery & \\
Elevated blood glucose $>200(4,6,13-19)$ & $\begin{array}{l}\text { Anesthesia team manages intra-operatively } \\
\text { Careful patient selection and thorough counseling }\end{array}$ \\
HIV posinal cord injury (15,19-21) & $\begin{array}{l}\text { Careful patient selection, thorough counseling, modify immune modulating } \\
\text { medications if able }\end{array}$ \\
Polysubstance abuse (19) & $\begin{array}{l}\text { Pre-operative counseling, drug/alcohol cessation } \\
\text { Revision surgery }\end{array}$ \\
Diabetes mellitus $(4,6,13-19)$ & Medical optimization; intra-operative glucose monitoring; anti-fungal prophylaxis \\
Prior Implant $(2,22)$ & Careful patient selection, thorough counseling \\
Biofilm $(2,23,24)$ & Peri-operative antibiotic selection, wound irrigation/washout \\
\hline
\end{tabular}

\section{Diagnosis}

IPP infections are classified as either immediate or indolent, depending on when they occur post-operatively. We use a cut-off of eight weeks to define the two groups. Immediate infections often manifest as surgical site infections with purulence, edema, etc. Patients may be clinically ill with fever and/or sepsis (7). These patients are most often easy to recognize. The majority of infections, however, are indolent and require clinical experience and judgement. These patients present with vague symptoms including pain, pump issues such as fixation to the skin and difficulty with maneuvering, and some may have draining sinus tracts (8). Whereas immediate infections are caused by aggressive bacteria such as staph aureus and gram negatives, indolent infections are often caused by skin flora such as staph epidermidis (9-11). It is hypothesized that indolent infections arise from hematogenous seeding in the setting of other procedures (12). It is crucial to recognize an indolent infection as early as possible.

\section{Risk factors}

Imperative to a discussion regarding a surgical complication is risk factors. Several studies have been conducted to examine risk factors given the feared complications and those that have been identified, including ways to target them, are outlined in Table 1. It is important to classify these into two groups-primary surgery and revision surgery. Infection rates at primary surgery are quoted to be from $1-3 \%$ and at revision surgery, this number more than triples to $10-18 \%(22,25)$.
Risk factors at primary surgery include comorbidities and behavioral risk factors $(2,26)$. Diabetes has been proposed to be an independent risk factor however, multiple studies have demonstrated that the diagnosis alone is not a risk factor but the risk is related to poorly controlled glucose at the time of the surgery. A level of $>200 \mathrm{mg} / \mathrm{dL}$ has been cited as a cutoff. These patients have been documented to have up to $4 \mathrm{X}$ increased infectious risk $(22,27)$. It is recommended to have frequent glucose checks intra-operatively and tight glucose control surrounding the procedure. Further risk factors at virgin implants include spinal cord injury, HIV positivity, and long-term immunosuppression for chronic disease. Decreasing these risk factors is more difficult and involves careful patient selection and pre-operative counseling. Some immunosuppression may be able to be modified surrounding the surgery depending on the type.

Risk factors at revision surgery are slightly different and it is imperative to acknowledge that having a revision surgery itself is an independent risk factor for infection and increases the risk from $1-3 \%$ to $10-18 \%(22,25)$. Additional risk factors unique to revision surgery include a diagnosis of diabetes, capsule formation, and biofilm.

\section{Biofilm}

Biofilm is secreted by bacteria, presumably brought into contact with the device as it passes through the skin, and becomes integrated into the corpora and sealed off by the body's surgical capsule. This biofilm provides nourishment to the bacteria and the surgical capsule wards off immune activity resulting in decreased antibiotic penetration and 
efficacy and challenges to the management overall of these infections $(23,24,28)$.

\section{Infection prevention}

There are three phases of potential intervention to decrease infection: pre-operative, intra-operative, and post-operative. Pre-operatively, patient selection and counseling cannot be emphasized enough. A thorough medical history and physical exam should be conducted. Any groin fungal rashes should be treated with oral fluconazole. While of low yield and questionable clinical relevance, urine cultures are often obtained (28). Similarly, Hb A1c levels are frequently checked pre-operatively but there has been no correlation in the literature regarding their relevance to outcomes (2). We do recommend nasal swabs to identify and treat carriers of S. aureus based on a randomized control trial demonstrating an $80 \%$ reduction in deep surgical site infections for patients with $\mathrm{s}$. aureus who were pre-treated with mupirocin and chlorhexidine (29). While not evidence based, high volume prosthetic surgeons recommend patients to bathe with chlorhexidine a few days before surgery (2). As discussed earlier, patients with a history of polysubstance abuse have an increased incidence of infection and in their study examining this, these patients had an $892 \%$ increased rate of infection compared to patients who did not have a history of polysubstance abuse (27). Patient selection cannot be emphasized enough.

For patients on anti-coagulation or blood thinning medication, we allow them to continue a baby aspirin through surgery but will hold other forms of anticoagulation. For high risk patients, consider using a lovenox bridge and holding lovenox for 24 hours peri-operatively before resuming.

On the day of surgery, a physical exam should be repeated. Hair should be removed with clippers instead of razors (30). IV antibiotics have undergone recent changes given the results of a large multicenter analysis revealing that isolated bacteria were resistant to the most commonly antibiotics in up to $1 / 3$ of cases (31). We recommend broad spectrum antibiotics to infuse at 1-2 hours pre-operatively and to last for 24 hours $(31,32)$. We routinely use vancomycin, gentamicin, and fluconazole. Current AUA Guidelines for prosthetic devices recommend an aminoglycoside and $1^{\text {st }} / 2^{\text {nd }}$ generation cephalosporin or vancomycin (33). While anti-fungal prophylaxis is not endorsed by the AUA, recent studies have examined fungal rates and have found them to be increasing. For high risk patients including diabetics, obese patients, and revision surgeries, we recommend fluconazole based on these data $(13,14)$.

Intra-operatively, infection retardant coating from device manufactures has contributed substantially to decreased infections with a meta-analysis revealing a $60 \%$ decrease in infections (15). Coloplast IPPs are soaked in antibiotic solution immediately before placement as they are absorptive. AMS devices are built with InhibiZone ${ }^{\circledR}$ which includes rifampin and gentamicin. In addition to using these devices, we recommend that all prosthetic cases, especially revision surgeries, be performed at high volume centers. This provides surgical expertise, a decrease in operative time, a consistent operative team including a recommended standardized checklist, and lower complication rates (2). Based on data from other surgical fields, we recommend prepping the surgical site with chlorhexidine-alcohol based solution and at all times minimizing contact with the skin, also referred to as the no touch technique (NTT) $(16-18,20)$. The anesthesia team should work on tight glycemic control and maintaining normothermia. Regarding the placement of a drain, a multicenter retrospective analysis revealed decreased postoperative hematoma but no change in infection rates (21). We do also recommend a wrap to reduce hematoma formation and specifically use the 'Mummy' wrap which has been associated with an $83 \%$ reduction in infection rates $(19,27)$.

Climate has recently been examined and found to be associated with increased infection rates. In their recent study, Gross et al. found increased infections in summer months and in increasingly humid climates. In addition, fungal infections occurred more frequently with increasing humidity and Gram positive organisms were seen more often in Fall/Spring climates than in Summer climates (34). When choosing peri-operative antibiotics, special note should be taken to identify all risk factors and treat appropriately.

Post-operatively, there is no data to support extended use of antibiotics beyond 24 hours. While most prosthetic surgeons continue their patients on home antibiotics, this is an area of sparse data and needs further investigation.

\section{Managing infections}

Whereas the original management of prosthetic infections was device explant with delayed reimplant, Mulcahy et al. introduced the salvage technique in 1996 that is now widely adapted although not universally utilized by prosthetic surgeons. In this procedure, the infected IPP is removed, the wound thoroughly irrigated, and a new 
device immediately implanted. They report a success rate of over $80 \%(7,14)$. Replacement of an IPP vs a malleable have both been described (35). A third technique described is the Carrion Cast which we do not recommend using in the absence of an experienced prosthetic surgeon. This technique involves injecting antibiotic impregnanted calcium sulfate into the corpora that dissolves over time and allows the corporal space to be preserved (36).

While there is no definitive guide on managing infected implants, we recommend the following First, the device should be cultured via direct swap or needle aspirate. Second, broad spectrum antibiotics including anti-fungal and anti-pseudomonas coverage should be administered and tailored once cultures finalize. Surgical procedures from this point are based on clinical judgement and patient wishes. If surgery is to be performed, the Mulcahy salvage with either a malleable or inflatable implant should be used. Antibiotics are routinely given for 4-6 weeks post-operatively. Again, expert opinion should be sought and thorough patient counseling is imperative.

\section{Conclusions}

Penile prosthesis infections are devastating. With attention to detail at the pre-operative, intra-operative, and postoperative setting, infectious risks can be minimized. The most common infections involve skin flora and present as indolent, often difficult to diagnose, vague complaints. Device cultures and broad spectrum antibiotics are mandated and while most infections will require explantation, some can be measured conservatively. Overall, these are best managed at centers of excellence by high volume prosthetic surgeons.

\section{Acknowledgments}

Funding: None.

\section{Footnote}

Provenance and Peer Review: This article was commissioned by the editorial office, Fournal of Visualized Surgery for the series "Penile Prosthesis Surgery". The article has undergone external peer review.

Conflicts of Interest: Both authors have completed the ICMJE uniform disclosure form (available at https://jovs.amegroups. com/article/view/10.21037/jovs.2020.01.05/coif). The series "Penile Prosthesis Surgery" was commissioned by the editorial office without any funding or sponsorship. MG served as an unpaid Guest Editor of the series and reports personal fees from Coloplast, outside the submitted work. The authors have no other conflicts of interest to declare.

Ethical Statement: The authors are accountable for all aspects of the work in ensuring that questions related to the accuracy or integrity of any part of the work are appropriately investigated and resolved.

Open Access Statement: This is an Open Access article distributed in accordance with the Creative Commons Attribution-NonCommercial-NoDerivs 4.0 International License (CC BY-NC-ND 4.0), which permits the noncommercial replication and distribution of the article with the strict proviso that no changes or edits are made and the original work is properly cited (including links to both the formal publication through the relevant DOI and the license). See: https://creativecommons.org/licenses/by-nc-nd/4.0/.

\section{References}

1. Montague DK, Jarow JP, Broderick GA, et al. The management of erectile dysfunction: an update. J Urol 2005;174:230-9.

2. Carrasquillo RJ, Gross MS. Infection prevention strategies prior to penile implant surgery. Eur Urol Focus 2018;4:317-20.

3. Selph JP, Carson CC 3rd. Penile prosthesis infection: approaches to prevention and treatment. Urol Clin North Am 2011;38:227-35.

4. Goetz A, Yu VL, O'Donnell WF. Surgical complications related to insertion of penile prostheses with emphasis on infection and cost. Infect Control Hosp Epidemiol 1988;9:250-4.

5. Pederzoli F, Chappidi MR, Collica S, et al. Analysis of hospital readmissions after prosthetic urologic surgery in the United States: nationally representative estimates of causes, costs, and predictive factors. J Sex Med 2017;14:1059-65.

6. Sunaryo PL, Colaco M, Terlecki R. Penile prostheses and the litigious patient: a legal database review. J Sex Med 2014;11:2589-94.

7. Mulcahy JJ. Long-term experience with salvage of infected penile implants. J Urol 2000;163:481-2.

8. Blum MD. Infections of genitourinary prostheses. Infect Dis Clin North Am 1989;3:259-74.

9. Mulcahy JJ. Penile prosthesis infection: progress in 
prevention and treatment. Curr Urol Rep 2010;11:400-4.

10. Carson CC. Diagnosis, treatment and prevention of penile prosthesis infection. Int J Impot Res 2003;15 Suppl 5:S139-46.

11. Wilson SK, Salem EA, Costerton W. Anti-infection dip suggestions for the Coloplast Titan Inflatable Penile Prosthesis in the era of the infection retardant coated implant. J Sex Med 2011;8:2647-54.

12. Carson CC, Robertson CN. Late hematogenous infection of penile prostheses. J Urol 1988;139:50-2.

13. Gross MS, Reinstatler L, Henry GD, et al. Multicenter investigation of fungal infections of inflatable penile prostheses. J Sex Med 2019;16:1100-5.

14. Brant MD, Ludlow JK, Mulcahy JJ. The prosthesis salvage operation: immediate replacement of the infected penile prosthesis. J Urol 1996;155:155-7.

15. Mandava SH, Serefoglu EC, Freier MT, et al. Infection retardant coated inflatable penile prostheses decrease the incidence of infection: a systematic review and metaanalysis. J Urol 2012;188:1855-60.

16. Darouiche RO, Wall MJ Jr, Itani KM, et al. Chlorhexidine-alcohol versus povidone-iodine for surgical-site antisepsis. N Engl J Med 2010;362:18-26.

17. Yeung LL, Grewal S, Bullock A, et al. A comparison of chlorhexidine_-alcohol versus povidone-iodine for eliminating skin flora before genitourinary prosthetic surgery: a randomized controlled trial. J Urol 2013;189:136-40.

18. Eid JF. No-touch technique. J Sex Med 2011;8:5-8.

19. Henry GD. The Henry mummy wrap and the Henry finger sweep surgical techniques. J Sex Med 2009;6:619-22.

20. Eid JF, Wilson SK, Cleves M, et al. Coated implants and "no touch" surgical technique decreases risk of infection in inflatable penile prosthesis implantation to $0.46 \%$. Urology 2012;79:1310-5.

21. Sadeghi-Nejad H, Ilbeigi P, Wilson SK, et al. Multiinstitutional outcome study on the efficacy of closedsuction drainage of the scrotum in three-piece inflatable penile prosthesis surgery. Int J Impot Res 2005;17:535-8.

22. Wilson SK, Delk JR 2nd. Inflatable penile implant infection: predisposing factors and treatment suggestions. J Urol 1995;153:659-61.

23. Costerton $W$, Veeh R, Shirtliff $M$, et al. The application of biofilm science to the study and control of chronic bacterial infections. J Clin Invest 2003;112:1466-77.

24. Stewart PS, Costerton JW. Antibiotic resistance of bacteria in biofilms. Lancet 2001;358:135-8.

25. Carson CC 3rd, Mulcahy JJ, Harsch MR. Long-term infection outcomes after original antibiotic impregnated inflatable penile prosthesis implants: up to 7.7 years of follow up. J Urol 2011;185:614-8.

26. Jarow JP. Risk factors for penile prosthetic infection. J Urol 1996;156:402-4.

27. Balen A, Gross MS, Phillips EA, et al. Active polysubstance abuse concurrent with surgery as a possible newly identified infection risk factor in inflatable penile prosthesis placement based on a retrospective analysis of health and socioeconomic factors. J Sex Med 2016;13:697-01.

28. Kavoussi NL, Siegel JA, Viers BR, et al. Preoperative urine culture results correlate poorly with bacteriology of urologic prosthetic device infections. J Sex Med 2017;14:163-8.

29. Bode LG, Kluytmans JA, Wertheim HF, et al. Preventing surgical site infections in nasal carriers of Staphylococcus aureus. N Engl J Med 2010;362:9-17.

30. Grober ED, Domes T, Fanipour M, et al. Preoperative hair removal on the male genitalia: clippers vs. razors. J Sex Med 2013;10:589-94.

31. Gross MS, Phillips EA, Carrasquillo RJ, et al. Multicenter investigation of the micro-organisms involved in penile prosthesis infection: an analysis of the efficacy of the AUA and EAU guidelines for penile prosthesis prophylaxis. J Sex Med 2017;14:455-63.

32. Rosenberger LH, Politano AD, Sawyer RG. The surgical care improvement project and prevention of post-operative infection, including surgical site infection. Surg Infect (Larchmt) 2011;12:163-8.

33. Wolf JS Jr, Bennett CJ, Dmochowski RR, et al. Best practice policy statement on urologic surgery antimicrobial prophylaxis. J Urol 2008;179:1379-90.

34. Gross MS, Vollstedt AJ, Cleves MA, et al. Multicenter investigation on the influence of climate in penile prosthesis infection. Int J Impot Res 2020;32:387-92.

35. Gross MS, Phillips EA, Balen A, et al. The malleable implant salvage technique: infection outcomes after Mulcahy salvage procedure and replacement of infected inflatable penile prosthesis with malleable prosthesis. J Urol 2016;195:694-7.

36. Swords K, Martinez DR, Lockhart JL, et al. A preliminary report on the usage of an intracorporal antibiotic cast with synthetic high purity $\mathrm{CaSO} 4$ for the treatment of infected penile implant. J Sex Med 2013;10:1162-9.

doi: 10.21037/jovs.2020.01.05

Cite this article as: Reinstatler L, Gross MS. Prevention and management of penile prosthesis infections. J Vis Surg 2021;7:6. 